\title{
USO DE PLANTAS MEDICINAIS COMO INSTRUMENTO DE CONSCIENTIZAÇÃO: RESPONSABILIDADE SOCIAL E AMBIENTAL
}

\author{
Benta Maria Martins dos Santos', Jumaida Maria Rosito² \\ ${ }^{1}$ Especialista em Educação Ambiental da Universidade Federal de Santa Maria (UFSM). \\ (bentadossantos@hotmail.com ) \\ ${ }^{2}$ Orientadora. Professora do Curso de Especialização em Educação Ambiental da Universidade Federal de Santa Maria \\ (UFSM). (jmrosito@gmail.com)
}

\section{RESUMO}

O presente trabalho teve como objetivo despertar nos alunos do $4^{\circ}$ ano do ensino fundamental de uma escola rural, no município de São Sepé, através do cultivo de plantas medicinais a consciência sobre a importância de seu uso correto e responsável,como recurso terápico. Foram trabalhadas as famílias e os alunos do 4 ㅇ ano da Escola Rural João Pessoa, no município de São Sepé (RS, Brasil). Ao longo do trabalho foram aplicados questionários para identificar meios de obtenção e de utilização de plantas medicinais, motivo para o uso, cultivo e forma de preparo. Dezenove espécies de plantas foram citadas pelos entrevistados; todos utilizam as plantas como primeiro recurso em caso de problemas de saúde considerados leves. Se forem considerados o envolvimento da comunidade nas atividades propostas e os desdobramentos do projeto em atividades em classe, as ações geradas pelo projeto (discussões, entrega de material de referência, jogos e debates) contribuíram para despertar o interesse pelo tema; como conseqüência. Pode-se dizer que a comunidade escolar foi sensibilizada com relação aos problemas envolvendo o uso das plantas medicinais, trato e cuidados exigidos para a manutenção desse recurso e, por extensão, a busca de qualidade de vida e a conservação do meio ambiente.

Palavras-chave: Plantas medicinais. Educação ambiental. Conscientização ambiental.

\section{ABSTRACT}

In Brazil the medicinal plants are used with little or none scientific evidence. This study had as the object the people knowledge and the awareness of the correct use of the medicinal plants with Escola Rural João Pessoa $4^{\circ}$ grade students families, at São Sepé Municipal District(RS, Brazil). During the study, questionnaires were applied to identify ways of obtaining and using medicinal plants, use motive, cultivation and preparing ways. About 20 plants were cited by the interviewed; all of them use the plants as the first resource in case of light considered health problems. If the community involvement at the proposed project activities and development in class, the actions created by the project (debates, regarding material turned in, games and argumentations) contributed to stimulate the interest to the topic; as a consequence, we can say that the school community were touched in relation to the problems involving the use of those plants, the deal and care demanded for these resource maintenance and, as extension, to the care with the natural resources, in a general way. 
Key words: Medicinal plants. Environmental education. Environmental conscience.

\section{INTRODUÇÃO}

A prática de utilização das plantas como medicamento é muito antiga; apesar disso, ainda há uma enorme quantidades de plantas sobre as quais, a medicina sabe muito pouco, ou mesmo nada conhece.

Seu uso parece ser mais generalizado entre a população indígena e de camponeses, mas o interesse por esse assunto tem se alastrado mesmo entre a população dos grandes centros. Devese destacar que, segundo Souza (1971), o indígena não apenas conhece o local de coleta das espécies vegetais utilizadas, mas também detém o saber ancestral sobre seu uso correto e os efeitos sobre a saúde de seu povo, o que pode significar a diferença entre a vida ou a morte. Segundo esse mesmo autor, o povo europeu parece ter decidido "encurtar o caminho", ou seja, tentou extrair do índio esse conhecimento, que era valioso, mas no contexto das patologias e da biota do continente americano.

Todas as plantas medicinais apresentam um nome cientifico, validado no mundo todo no entanto são reconhecido pelas pessoas, por um nome popular, regionalmente. Para maior segurança na utilização desse recurso, é fundamental que se conheça as duas nomenclaturas (CORREIA JÚNIOR et al, 1994). O conhecimento das plantas medicinais apenas pelo seu nome popular pode gerar dúvidas e enganos na sua utilização, como acontece, por exemplo, com a "espinheira-santa"; existem várias espécies comercializadas com esse nome, algumas delas sem efeito comprovado.

Parece claro, portanto, que o incentivo à identificação correta de espécies medicinais, as informações sobre seu uso adequado e manejo, são práticas saudáveis que contribuirão para a saúde das populações humanas e para a preservação desse recurso, cada vez mais valorizado.

Sob outro aspecto, Mendonça (1998) acredita que o poder curativo das plantas não pode ser visto apenas como uma tradição passada de pai para filho, mas sim, como um conhecimento que deve ser estudado e aperfeiçoado para que possa ser aplicado de forma mais segura e eficaz possível pelo usuário. Contudo, quando o assunto são as plantas medicinais, é comum perceber que a cultura e a ciência, nem sempre, andam de mãos dadas. O local onde a maioria das pessoas adquire as ervas medicinais e seu estado de conservação é outro problema que pode até se tornar um risco a saúde. Muitas ervas são vendidas na rua ou expostas ao ar livre em feiras e mercados populares, quando o correto seria que essas plantas fossem vendidas embaladas e beneficiadas, de forma adequada.

A medicina jamais contestou o poder das plantas, mas condena seu uso indiscriminado, sem orientação. A diferença entre o remédio e um veneno pode ser uma simples questão de dosagem. Além do perigo da identificação incorreta, a auto-medicação é um assunto preocupante.

Outro aspecto interessante desse tema é o conhecimento acerca das plantas medicinais visando à preservação desse recurso e sua valorização. Cada espécie empresta suas raízes, caule, folhas ou mesmo flores para a obtenção de chás ou outras beberagens. Sua coleta indiscriminada pode levar ao extermínio de populações inteiras. A própria "espinheira-santa" (Maytenus ilicifolia Mart.), tem as raízes largamente utilizadas para casos de úlceras estomacais (SIMÕES ET al.,2000). 
No entanto, as folhas dessa espécie podem ser utilizadas, da mesma maneira, sem que seja necessário exterminar um indivíduo para a obtenção do medicamento.

Esse trabalho foi desenvolvido com alunos de uma escola municipal de São Sepé (RS); com aproximadamente cento e setenta alunos e dezoito professores, funciona com calendário alternativo em horário integral; os alunos chegam de transporte escolar oferecido pelo município e supervisionado pela secretaria Municipal de Educação e cultura. A comunidade tem como característica econômica a produção agrícola e agropecuária; portanto, os alunos da escola são, em sua maioria, filhos de trabalhadores rurais, pequenos produtores que se dedicam à agricultura familiar, proprietários ou arrendatários de áreas de produção de arroz ou criação de gado.

A realidade rural dos alunos, aliada às dificuldades socioeconômicas enfrentadas pela maioria dos familiares, trás grandes preocupações no sentido de falta de acesso aos meios de cultura, lazer e das tecnologias de informação e comunicação, refletindo essas questões nas dificuldades de aprendizagem dos educandos.

A comunidade escolar está engajada na luta pela unidade e transformação da educação, através de estudos e projetos que visam o resgate dos valores humanos, ambientais de cooperação e cidadania, proporcionando um novo sentido à vida escolar para que os alunos possam ser pessoas realmente empreendedoras e atuantes em nossa sociedade.

O objetivo principal desse trabalho foi despertar nos alunos do $4^{\circ}$. ano do ensino fundamental de uma escola publica na zona rural no município de São Sepé (RS), através do cultivo de plantas medicinais, a importância de seu uso correto e responsável como recurso terápico e como parte a ser preservada do meio em que vivemos.. Além disso, esperava-se que o acompanhamento do seu plantio e desenvolvimento e o fomento de discussões sobre o tema, reforçassem nos educados uma atitude positiva em relação à preservação da vida, utilização correta dos recursos naturais e seu aproveitamento responsável. Essa conscientização, se levada para o ambiente familiar e a comunidade em geral, potencializa os resultados obtidos.

\section{REVISÃO BIBLIOGRÁFICA}

A comunidade foi sensibilizada para o cuidado com as plantas de seu interesse; essa sensibilização abriu um canal de ligação com os outros aspectos da relação homem $x$ ambiente. Tais ações ajudaram a conscientizar e preservar os recursos naturais indispensáveis a vida e, sabese que se houver participação da família e escola, tornam-se mais prazerosa para a criança, o que é determinante para o seu desenvolvimento social.

As investigações botânicas mais aprofundadas sobre o uso e o conhecimento de plantas medicinais podem contribuir para melhorar o entendimento do processo de aquisição e perda do conhecimento em uma determinada comunidade (AMOROZO, 2002). Nesse contexto, Albuquerque e Andrade (2002) assinala que todas as ciências que se ocupam em investigar a relação pessoas/plantas estão preocupadas em registrar e conhecer as estratégias e conhecimentos dos povos locais, procurando também usar essa informação em benefício dessas próprias pessoas. Assim, os estudos relacionados com a medicina popular têm merecido cada vez maior atenção, em virtude da gama de informações e esclarecimento à ciência. Segundo GuarimNeto et al. (2000), é através da etnobotânica que se busca o conhecimento e o resgate do saber botânico tradicional, particularmente relacionado ao uso dos recursos da flora. 
Como destaca Morin (2000) a Ecologia é uma ciência interdisciplinar que necessita relacionar-se com outras ciências para compreender as interações existentes entre os seres na Biosfera. Desta maneira, a Educação Ambiental, também não está dissociada da inter-relação entre as diferentes disciplinas, da interdisciplinaridade. Como afirma CASCINO (1998), a Educação Ambiental não contém especificidade isolada, corresponde a uma transformação de toda a educação, a um fazer educação mais ampla.

Assim cada vez mais podemos perceber que a medicina popular pode auxiliar e muito a medicina convencional, mas para isso são necessários estudos mais aprofundados sobre as plantas medicinais e uma interação maior entre a medicina convencional e as pessoas que utilizam essas plantas, para que haja uma troca de experiência e conhecimento.

Matos (1999) observa que, planta medicinal é medicamento apenas quando usada corretamente. Para conseguir esse uso correto é necessário, em princípio, atender às recomendações da Organização Mundial de Saúde quanto ao aproveitamento das plantas medicinais nos programas de saúde pública, como forma de diminuir os custos e ampliar o número de benefícios desses programas.

A Educação Ambiental emerge como indicador na busca pela sensibilização da população primando intensamente pelas questões ambientais, além das questões sociais, e o bem-estar da coletividade.

\begin{abstract}
A relação entre o conhecimento popular e o conhecimento científico pode ser enquadrada dentro da visão dialética que prevê a transformação e a educação das idéias. $O$ conhecimento popular, por um lado, associado com plantas mágicas e religiosas, leva a questionamentos na tentativa de se dar uma compreensão mais racional ao método terapêutico. Por outro lado o conhecimento científico estabelece uma relação racional entre o uso das plantas medicinais e a cura das doenças. A síntese entre esses dois pontos de vista é alcançada quando os pesquisadores, em busca de novas fontes de substâncias biologicamente ativas, vão até a população para efetuarem levantamentos etnobotânicos e, a partir destes, realizarem pesquisas laboratoriais (CASTRO et al. 2001, p.19).
\end{abstract}

Apesar de a herança cultural ter sido a maior fonte de aprendizagem a respeito de plantas com utilização medicinal, existe um grande interesse por parte dos entrevistados adquirir maiores informações sobre o uso e cultivo das mesmas, que invariavelmente recorrem as fontes externas como livros, revistas.

\title{
2 MATERIAL E MÉTODOS
}

O trabalho foi realizado com uma turma de 17 alunos do 4‥ ano da Escola Municipal de Ensino Fundamental João Pessoa, situada na zona rural do Distrito de Tupanci, Município de São Sepé (RS, Brasil). Despertou o aprofundamento teórico sobre o assunto, mas, buscou-se o envolvimento de toda a comunidade em torno do tema gerador - plantas medicinais, para que todos refletissem sobre valores de cidadania e ambiente.

Foram desenvolvidas atividades práticas para que os alunos tivessem um maior contato com as plantas medicinais reconhecendo e diferenciando cada uma.

Estimular nos alunos a consciência no que diz respeito aos impactos de suas ações no cotidiano, visa favorecer uma postura reflexiva que os leve a adotar valores e atitudes em relação ao uso correto de plantas medicinais e os perigos do seu uso. 
O trabalho foi realizado em etapas pela professora Benta Martins dos Santos: documentado através de fotografias e identificação das plantas medicinais a partir da lista da ANVISA (Agência Nacional de Vigilância Sanitária).

1a Etapa: Questionário:

Para avaliar quais as plantas medicinais conhecidas pela comunidade, foi distribuído um questionário semi-estruturado aos alunos, para que levassem às suas famílias (figura 1). Essa entrevista através de perguntas enfocava as plantas utilizadas, costumes e conhecimento de cada família a seu respeito, com o intuito de obter informações sobre o uso, preparo e sua utilização pela comunidade. Todos os dezessete questionários distribuídos foram respondidos e devolvidos. Essa etapa foi efetivada em novembro de 2010.

Após os alunos retornarem com os questionários foram realizadas discussões sobre as entrevistas, tentando expor todas as informações relevantes dos questionários, analisando as novas informações trazidas sobre o uso das plantas medicinais os cuidados que devemos ter ao preparar essas plantas para o uso.

2a Etapa: Escolha das espécies

A partir das plantas medicinais mais comumente citadas, foi solicitado às famílias envolvidas mudas, para transplante na área da Escola.

3a Etapa: Preparo dos canteiros

$\mathrm{Na}$ escola, na área previamente destinada ao transplante das mudas, foram preparados os canteiros, com a ajuda dos alunos e professores envolvidos. Os alunos foram despertados para a necessidade do preparo correto da terra, da escolha apropriada do lugar e dos tratos de manejo para o plantio.

4a Etapa: Transplante de mudas

Os alunos realizaram o plantio das espécies escolhidas e cedidas pelas famílias, tornandose, a partir daí, responsáveis pelo controle e manejo das espécies cultivadas.

5a Etapa: Conscientização e Responsabilidade Ambiental

Nessa fase, os alunos foram informados sobre os aspectos positivos e negativos do uso de plantas medicinais. Em especial, tiveram acesso à lista publicada pela Agência nacional de Vigilância Sanitária, em 11 de dezembro de 2011 (ANVISA, 2010) onde, pela primeira vez, algumas espécies medicinais têm seu uso e preparo regulamentado, além de terem destacados seus possíveis efeitos colaterais em decorrência do mau uso.

A partir da participação em todos os momentos do trabalho, os alunos tiveram condições de levar às famílias informações corretas sobre o uso de plantas medicinais, através de uma cartilha elaborada por eles, com as espécies cultivadas na Escola.

Desta forma os alunos decidiram, em conjunto, qual o destino das mudas que serviram de objeto para esse estudo, como forma de estimular a responsabilidade ambiental.

\section{RESULTADOS E DISCUSSÃO}

\subsection{Espécies utilizadas como medicinais}

Segundo os questionários, realizados com uma turma de 17 alunos do 4ㅇ. ano da Escola Municipal de Ensino Fundamental João Pessoa, situada na zona rural do Distrito de Tupanci, 
Município de São Sepé (RS, Brasil), 100\% dos entrevistados responderam que já utilizaram plantas medicinais como recursos em algum momento da vida, principalmente quando sofrem de algum mal considerado por eles mais simples, como dor de cabeça, estomacal, barriga; segundo eles, adotam esse procedimento pelo difícil acesso às unidades de saúde

Foi constatado, também, que todos fazem uso, também, de plantas medicinais como primeira alternativa no tratamento de enfermidades mais comuns; essas pessoas relataram ainda que, se não houver melhora, procuram um médico e, aí sim, fazem uso de medicamentos industrializados.

As pessoas entrevistadas disseram que também cultivam plantas medicinais em seus quintais e jardins.

Foram listadas dezenove espécies de plantas utilizadas pelos entrevistados, para fins variados, conforme o Quadro 1; nesse quadro consta ainda o provável nome científico da espécie mencionada, sua família botânica e algumas observações de uso, a partir do relato dos entrevistados. Faz-se necessário mencionar que o questionário, construído para ser respondido por leigos, trouxe informações sobre as plantas mais utilizadas segundo seu nome popular. O(s) binômio(s) científico(s) sugerido(s) no Quadro 2, faz referência às plantas mais comumente usadas no Rio Grande do Sul, segundo o nome popular mencionado pelos entrevistados.

Houve, portanto, certa dificuldade quanto à identificação segura das espécies citadas pelo nome popular; algumas delas são referências a várias espécies do mesmo gênero, como por exemplo, boldo, carqueja e malva (Quadro 2). Da mesma forma, espécies de gêneros diferentes podem apresentar o mesmo nome comum, como pode acontecer com erva-cidreira e poejo. Essa dificuldade é inerente ao uso dos nomes populares, que devem ser usados com restrições no momento da indicação de plantas medicinais para qualquer fim (Vendrusculo et al., 2005). 0 alerta com relação a essas confusões nomenclaturas é muito importante para que as comunidades possam utilizar as plantas medicinais de forma correta.

Deve-se salientar ainda, que em sete questionários, nas observações, foram transcritos comentários encontrados, o que significa que, a informação pode não ser um consenso entre os entrevistados.

\begin{tabular}{|c|c|c|c|}
\hline $\begin{array}{l}\text { Nome } \\
\text { popular }\end{array}$ & $\begin{array}{c}\text { Provável binômio científico (família } \\
\text { botânica) }\end{array}$ & Indicação & Observações das famílias \\
\hline Abacate & Persea americana Mill. (Lauraceae) & $\begin{array}{c}\text { Diurético, laxante e } \\
\text { digestivo. }\end{array}$ & $\begin{array}{l}\text { A parte utilizada foi à } \\
\text { folha. }\end{array}$ \\
\hline Alho & Allium sativumL.(Amaryelidaceal) & $\begin{array}{c}\text { Resfriado, tosse, febre, } \\
\text { inflamação da garganta, } \\
\text { vermes. }\end{array}$ & $\begin{array}{l}\text { Colocar de dois a três } \\
\text { dentes de alho em um } \\
\text { copo com água, à noite e } \\
\text { tomar pela manhã. }\end{array}$ \\
\hline Ameixa & Eriobotrya japonica Lindl. (Rosaceae) & $\begin{array}{l}\text { Diarréia e incontinência } \\
\text { urinária. }\end{array}$ & \\
\hline Anador & Alternanthera Ap. (Amaranthaceae) & Dores em geral. & $\begin{array}{l}\text { Usado pelos alunos na } \\
\text { escola }\end{array}$ \\
\hline Batata-doce & $\begin{array}{c}\text { Ipomoea batatas (L.) Lam. } \\
\text { (Convolvulaceae) }\end{array}$ & dor na bexiga & Usado com raiz de salsa. \\
\hline Boldo & $\begin{array}{c}\text { Plectranthus barbatus Andr. } \\
\text { (Lamiaceae), Plectruthus, neschilus }\end{array}$ & $\begin{array}{c}\text { Dor de estômago e } \\
\text { náuseas. }\end{array}$ & \\
\hline Carqueja & Baccharis trimera (Less) DC. & Afecções do estômago, & \\
\hline
\end{tabular}

http://cascavel.ufsm.br/revistas/ojs-2.2.2/index.php/remoa 


\begin{tabular}{|c|c|c|c|}
\hline & (Asteraceae) e outras & $\begin{array}{c}\text { fígado e para favorecer o } \\
\text { emagrecimento. }\end{array}$ & \\
\hline Chuchu & $\begin{array}{l}\text { Sechium edule (Jacq.) Sw. } \\
\text { (Cucurbitaceae) }\end{array}$ & $\begin{array}{l}\text { Para diminuir a pressão } \\
\text { alta e infecções renais. }\end{array}$ & \\
\hline Erva-cidreira & Aloysia triphylla Royle (Verbenaceae) & Calmante. & $\begin{array}{c}\text { Deve ser fraco, pois baixa } \\
\text { a pressão arterial. }\end{array}$ \\
\hline Erva-doce & Pimpinela anisum L. (Apiaceae) & Cólica em bebês. & \\
\hline Funcho & Foeniculum vulgare Mill. (Apiaceae) & Cólica em bebês. & \\
\hline Guaco & Mikania sm. (Asteraceae) & $\begin{array}{l}\text { Tosse, resfriado e } \\
\text { infecções do aparelho } \\
\text { respiratório. }\end{array}$ & \\
\hline Hortelã & Mentha sm. (Lamiaceae) & Vermes e boa digestão. & \\
\hline Laranjeira & $\begin{array}{l}\text { Citrus } X \text { sinensis (L.) Osbeck } \\
\text { (Rutaceae) }\end{array}$ & $\begin{array}{l}\text { Calmante, insônia e } \\
\text { ansiedade. }\end{array}$ & \\
\hline Lima & $\begin{array}{l}\text { Citrus aurantifolia (Christm.) Swingle } \\
\text { (Rutaceae) }\end{array}$ & $\begin{array}{l}\text { Evitar icterícia em recém- } \\
\text { nascidos. }\end{array}$ & $\begin{array}{c}\text { Com o chá preparado, dar } \\
\text { banho e fazer a criança } \\
\text { ingerir. }\end{array}$ \\
\hline
\end{tabular}

\begin{tabular}{|c|c|c|c|}
\hline Macela & $\begin{array}{l}\text { Achyrocline satureoides (Lam.) DC. } \\
\text { (Asteraceae) }\end{array}$ & $\begin{array}{l}\text { Dor de estômago e } \\
\text { cólicas. }\end{array}$ & \\
\hline Malva & $\begin{array}{l}\text { Malva parviflora L., M. silvestris L. } \\
\text { (Malvaceae) }\end{array}$ & $\begin{array}{l}\text { Para qualquer tipo de } \\
\text { inflamação. }\end{array}$ & $\begin{array}{l}\text { Não pode ser usado } \\
\text { quente, mas morno. }\end{array}$ \\
\hline Poejo & $\begin{array}{l}\text { Cunila microcephala Benth. } \\
\text { (Lamiaceae) }\end{array}$ & $\begin{array}{l}\text { Gripe, pressão arterial } \\
\text { alta, tosse e rouquidão. }\end{array}$ & \\
\hline Salsa & $\begin{array}{l}\text { Petroselinum crispum (Mill.) Fuss. } \\
\text { (Apiaceae) }\end{array}$ & $\begin{array}{l}\text { A raiz, junto com a } \\
\text { batata-doce, é usada para } \\
\text { dor na bexiga. }\end{array}$ & \\
\hline
\end{tabular}

Quadro 1. Espécies de plantas utilizadas como medicinais pelas famílias de alunos do $4^{\circ}$ ano do ensino fundamental da Escola João Pessoa, Distrito de São Sepé (RS).

O uso de plantas medicinais pelas populações deriva de um conhecimento empírico, passado através das gerações; esse conhecimento, nem sempre encontra embasamento científico. O chá da folha do abacate, por exemplo, é citado na literatura como antidiarrêico (LORENZI; MATOS, 2008), e como laxante, pelas famílias entrevistadas. O seu uso como diurético, também pode ser contestado; Lorenzi e Matos (2008), afirmam que o uso do chá provoca o aumento no total diário do número de micções, porém não aumenta o volume urinário, no mesmo período; segundo os autores, esse resultado explicaria a crença, mas não a justificaria. Já o trabalho "Flora Regional na medicina Caseira" (RONDÔNIA, 1986), recomenda o chá das folhas dessa espécie para dores renais, o que parece estar relacionado com a propriedade "diurética" referida pelos entrevistados. Provavelmente relacionado a seu efeito laxante, Garlet e Irgang (2001) relatam o uso desse chá para baixar a pressão arterial, conforme relatos de trabalhadoras rurais de Cruz Alta (RS). Vendrusculo et al (2008), referem a escassez de estudos sobre as propriedades terapêuticas dessa espécie; além disso, comentam sobre o perigo da ingestão do chá durante a gravidez e sobre relatos de intoxicação em animais pelo consumo de folhas e polpa do fruto. 
Com relação a outras espécies, como o alho, existe um consenso entre o uso popular e os estudos dirigidos por Instituições de Pesquisa; o alho é um exemplo. Mas, embora lhe sejam atribuídas inúmeras propriedades medicinais, Agência Nacional de Vigilância Sanitária (ANVISA, 2010), refere seu uso em casos de colesterol elevado, como expectorante e anti-séptico. No presente estudo, a comunidade entrevistada faz uso dessa espécie para usos diversos, como resfriado, tosse, febre, inflamação da garganta e vermes. Outros usos são

referidos, ainda, por Garlet e Irgang (2001), como lenitivo contra picada de aranha; os autores confirmam o uso popular de alho para gripes e infecções.

A planta medicinal conhecida por "Anador" abrange várias espécies do gênero Alternanthera (Garlet e Irgang, 2002; Vendrusculo et al, 2005), e é uma comprovação de que o nome popular não é uma informação confiável, no que tange ao uso de espécies medicinais. $A$. dentata, $A$. tenella e $A$. paronichyoides são conhecidas pelo mesmo nome vulgar, e segundo análise bibliográfica têm uso nas dores em geral, informação confirmada pela população alvo desse trabalho.

A batata-doce, segundo Lorenzi e Matos (2008), tem atividade antimicrobiana, talvez por isso, tenha sido referida como eficaz em "dores da bexiga", propriedade também verificada por Garlet e Irgang (2001).

O conhecido "boldo" é um nome popular aplicado a muitas espécies, inclusive de gêneros diferentes (Lorenzi e Matos, 2008). O boldo é uma arvoreta da espécie Chenopodium ambrosioides L. segue-se, ainda uma série de espécies do gênero Plectranthus e ainda a espécie Vernonia condensata Baker., todas elas usadas em males do estômago e fígado, o que confirma o uso referido nesse trabalho. O mesmo ocorre com a carqueja ou carquejinha. A ANVISA reconhece o uso de partes aéreas de $B$. trimera em distúrbios da digestão (ANVISA, 2010). Garlet e Irgang (2001) citam ainda B. gaudichauniana e Lorenzi e Matos (2008), várias espécies que atendem pelos nomes populares de carqueja-miúda, carqueja-amarga, carqueja-amargosa, carquejacomum, carqueja-do-mato.

Quanto à erva-cidreira, é comum a confusão, em função do nome popular, com capimcidró, Cymbopogon citratus (DC.) Stapf. Esse fato torna um pouco difícil o reconhecimento da espécie citada no questionário enviado às famílias. Em todo caso, ambas as espécies são mencionadas na literatura como calmantes, e apresenta o mesmo óleo essencial, o citral.

A erva-doce, reconhecida como medicinal pela ANVISA (2010), é usada popularmente contra cólicas, conforme o referido pela pesquisa; para o mesmo fim a medicina popular utiliza o funcho; ambas as espécies apresentam o anetol como óleo essencial predominante.

A comunidade-alvo dessa pesquisa refere o uso do guaco para tosse, resfriado e infecções do aparelho respiratório. Esse uso também é referido por Lorenzi e Matos (2001), e Garlet e Irgang (2001), que citam Mikania laevigata Sch. Bip. ex Baker e M. glomerata Spreng., para uma comunidade rural de Cruz Alta (RS).

No que tange à planta conhecida popularmente como hortelã, existe muita controvérsia na literatura. Alguns autores citam várias espécies de Mentha (Rondônia, 1986; Lorenzi e Matos, 2008); outros como Garlet e Irgang (2001), consideram um híbrido: Mentha X rotundifolia (L.) Huds. Independente da discordância taxonômica, o uso de espécies conhecidas popularmente como "hortelã" tem várias finalidades: tônico digestivo, como referido na pesquisa, vermífugo, calmante, entre outros. 
As famílias entrevistadas referiram o uso de chá de laranjeira como calmante e ansiolítico. Esse uso é confirmado por alguns trabalhos (Rondônia, 1986; Vendrusculo et al., 2008), mas, em outros, essa planta é citada no tratamento contra tosse, sendo que seu efeito calmante não é referido. A ANVISA (2010) menciona a laranja-amarga (Citrus aurantium L.), como calmante suave. Outra espécie do mesmo gênero, $C$. aurantifolia, citada como eficaz no tratamento de icterícia em recém-nascidos, é utilizada, segundo Garlet e Irgang (2001), como calmante, hipotensor, efetivo no tratamento contra gastrite e corrimento, sem referências ao uso citado.

A marcela é referendada pela ANVISA (2010, como atuante no tratamento contra cólicas, entre outras indicações, o que corrobora as informações obtidas através do questionário).

A planta conhecida como malva citada como eficiente no tratamento de qualquer tipo de inflamação, é referida na literatura para o mesmo fim (Lorenzi e Matos, 2008; Garlet e Irgang, 2001). M. sylvestris L. é também citada como "malva", e é utilizada na comunidade de Dom Pedro Alcântara (RS), segundo trabalho de Marodin et al., 2001. Essa mesma espécie é citada como medicinal pela ANVISA (2010).

O poejo foi citado nos questionário para uso em diferentes situações: para gripe, pressão arterial alta, tosse e rouquidão. $O$ uso contra tosse é referendado pelo trabalho de Garlet e Irgang (2001). Segundo Marodin e Baptista. (2001), esse é um dos nomes populares que causa confusão, uma vez que outra espécie bastante usada - Mentha pulegium L., também é chamada de "poejo". Para essa espécie, a ANVISA (2010) refere o uso de planta medicinal para o tratamento de afecções respiratórias e expectorante, entre outras.

Por último, os questionários apontam para a salsa como planta medicinal eficiente no tratamento, quando utilizada juntamente com a batata-doce, para atenuar a dor na bexiga. (Vendrusculo et al. 2008), Garlet e Irgang (2001) e Lorenzi e Matos (2008), confirmam o uso dessa espécie nas afecções de bexiga, mas não foram encontradas referências do uso de salsa associado à batata-doce, como referido nesse trabalho.

Segundo a Organização Mundial de Saúde (OMS), "planta medicinal" é toda planta que administrada ao homem ou animal, por qualquer via ou forma, exerça alguma ação terapêutica. $O$ tratamento feito com o uso de plantas medicinais é denominado de fitoterapia, e os fitoterápicos são os medicamentos produzidos a partir dessas plantas.

Dias (2002) afirma, entretanto, que é importante a orientação quanto ao cultivo e manejo correto das plantas medicinais, pois a complementação do conhecimento popular e científico sobre a produção e o uso de plantas medicinais é fundamental para sua segurança e eficácia.

No entanto as famílias entrevistadas responderam que tem conhecimento sobre alguns perigos do uso incorreto de plantas medicinais; salientaram, ainda, o conhecimento de que uma espécie pode ser benéfica na solução de um problema, mas ser prejudicial a outro aspecto da saúde.

Embora todos acreditem que os chás caseiros também possam ter contra-indicações, dez dos entrevistados comentaram desconhecerem algum caso real de mal-estar causado por plantas medicinais.

Embora se saiba que é um consenso, um dos entrevistados manifestou a crença de que os chás são muito importantes por serem medicamentos naturais, por tanto, sem uso de química, e que, em alguns casos, substitui o remédio (alopático). 
Todos os entrevistados responderam que preparam o chá na forma de infusão, isso é, colocam em um recipiente as folhas ou flores da planta, conforme o caso cobre com água bem quente e abafam com uma tampa; o chá é ingerido ainda quente ou morno, conforme o caso.

Segundo um dos entrevistados, algumas infusões podem ser tomadas em temperatura elevada outras não, conforme conhecimentos adquiridos de suas avós e mães. Conforme Lorenzi (2001), plantas medicinais são medicamentos somente quando usado corretamente, portanto a recomendação do seu uso como planta medicinal validada e incluída na farmacopéia requer uma condição ideal de identificar o seu principio ativo ecologicamente. Nesse contexto o uso de cada tipo de planta é indicado a um determinado distúrbio e para saber a utilização correta deve-se recorrer a um profissional especializado (SOSSAE, 2006). Numa população com baixo acesso a medicamentos, como a brasileira, agregar garantias científicas a essa prática terapêutica traz variadas vantagens (BARATA, 2003). Para que uma planta seja utilizada como fototerápico na medicina popular é necessária a obtenção do seu reconhecimento científico. Para este estudo, a escolha das plantas inicia-se a partir de um levantamento etnobotânico, seguido do levantamento bibliográfico e experimentação em laboratório. As informações geradas são organizadas em um banco de dados e, posteriormente, sua eficácia e segurança terapêutica é avaliada. (SIMÕES et al., 2000)

A informação e conscientização são fundamentais para que o uso das plantas seja realmente proveitoso; conhecer cada planta, entender como ela age no organismo e a forma correta de preparo e armazenagem são fundamentais para assim obtermos resultados satisfatórios. Desta forma os profissionais de saúde, agente domiciliares devem ter conhecimentos sobre o uso, efeitos, benefícios e riscos para prestar esclarecimentos corretos, sobre como aproveitar melhor o principio ativo de cada planta, bem como o uso inadequado.

cultivo das mesmas, que invariavelmente recorrem a fontes externas como livros, revistas.

A utilização de plantas no tratamento de saúde apresenta um método prático porém só há resultados positivos quando usado com responsabilidade. A construção desse respeito e conhecimento passa pode ser feita de diversas maneiras; no âmbito desse trabalho, acredita-se que a construção de textos, materiais ilustrados, cruzadinhas, caça-palavras e da cartilha, recursos didáticos utilizados em aula, sejam uma contribuição relevante na diminuição gradativa dos casos de uso indevido das plantas medicinais; esperam-se, da mesma forma, que esses procedimentos sirvam como instrumento para transmitir informações corretas, conhecimentos, visando uma melhor qualidade de vida com saúde e cidadania.

De acordo com a pesquisa na comunidade, as famílias mostraram que conhecem a região onde vivem, sendo que as mulheres dominam o conhecimento passado de geração a geração, tratando-se do uso de plantas medicinais para o tratamento de algumas enfermidades.

Espera-se que essas crianças sejam multiplicadoras do tema abordado, sensibilizando as famílias com as quais convivem sobre a necessidade e a importância do uso correto das plantas medicinais, assim como da preservação do meio ambiente, fonte de todo esse material a ser explorado.

As famílias entrevistadas relatam nos questionários já terem utilizado algumas vezes as plantas medicinais como um recurso para sanar algumas enfermidades ao longo de sua vida. Entende-se que grande parte dos consumidores de plantas medicinais sente-se encorajado por acreditarem que estes remédios, por serem naturais, não possuem contra-indicações. 
“De acordo com (Amorozo, 2000) as investigações botânicas mais aprofundadas sobre o uso e o conhecimento de plantas medicinais podem contribuir para melhorar o entendimento do processo de aquisição e perda do conhecimento em uma determinada comunidade."

Quanto à cartilha elaborada durante a realização do trabalho espera-se que sirva como instrumento para transmitir informações corretas, conhecimentos, visando uma melhor qualidade de vida com saúde e cidadania.

Nessa perspectiva deve-se ter o entendimento de que a saúde tem uma dimensão pessoal que se expressa no espaço e no tempo de uma vida, pelos meios que cada ser humano dispõe para criar seu próprio trajeto em direção ao bem estar físico, mental e social. Isso requer sujeitos com identidade, liberdade e capacidade para regulamentar as variações que aparecem no organismo que se apropriem de meios para tomar medidas práticas de auto cuidado em geral, e especificamente diante de situações de risco.

Para atender a essa meta é necessário que o trabalho educativo tenha como referencia as transformações próprias do crescimento e desenvolvimento humano e promova uma consciência critica em relação aos fatores que entrevem positivamente e negativamente. Para que assim possam conhecer-se e cuidar-se, valorizando sua saúde com maiores esclarecimentos quanto ao uso de plantas medicinais possibilitando melhores resultados, para que as mesmas não confundam suas propriedades curativas comprovadas cientificamente.

A experiência trazida consegue ao longo de suas vidas serão contempladas na escola, com busca de informações, análise, reflexões, conhecimentos e integração estabelecendo relação de dialogo dentro do processo formativo.

Esse trabalho buscou, além de tudo, resgatar saberes antigos que possam contribuir para saúde e bem estar das famílias.

Como diz Morin (2000),"A grande esperança para o século XXI é cidadania terrestre, cujo os embriões podem ser germinados através da educação,ao possibilitar a transmissão do antigo e abrir a mente para o novo". Nesse pressuposto a escola é um espaço social e local onde o aluno dará seqüência ao seu processo de socialização, visando meios efetivos para que o aluno compreenda as ações humanas e suas conseqüências para si mesmo e outros seres vivos do ambiente, aprender a viver orientados por atitude de respeito e cuidado com o meio ambiente, nutre e possibilita o desenvolvimento de todas as suas possibilidades humanas: Terra o grande organismo que eles fazem parte.

\section{CONSIDERAÇÕES FINAIS}

É importante lembrar que é dever da escola e dos educadores incluir e situar o aluno no meio em que ele vive, instigando-o a ampliar seus conhecimentos sobre a biodiversidade e seu ambiente. Uma fonte rica de informações e pesquisa que está muito próxima de todos eles - seus quintais, especialmente este caso, um distrito, em que a maioria das pessoas vive como uma comunidade; as casas têm quintais e plantas diversas, e há troca de saberes, pois quase todos os moradores se conhecem. Os alunos ficam orgulhosos de ver seus conhecidos e parentes participando das oficinas, ensinando na escola deles. Acreditamos que é importante promover, cada vez mais, ações de conscientização, nas escolas, nas instituições e em diferentes ambientes. Desta forma entende-se que é necessário que o aluno perceba seu valor, torne-se parte integrante 
do meio ambiente e sujeitos ativos da sociedade, responsáveis pelas suas atitudes. Então cabe à escola, juntamente com a família, o desafio de orientá-los para que no futuro sejam adultos conscientes nas questões ambientais; proporcionar oportunidades para que o aluno possa utilizar o conhecimento sobre recursos naturais para compreender sua realidade e atuar sobre ela. A ação de preservação do meio ambiente exige de cada um de nós um aprendizado, algo a ser desenvolvido por toda nossa vida.

\section{CONCLUSÕES}

O trabalho alcançou seu objetivo, na medida em que contribuiu para despertar a consciência sobre o uso responsável de plantas medicinais; através desse tema gerador, as crianças foram sensibilizadas para o cuidado com as coisas da natureza e a importância do conhecimento que preserva. Houve integração entre família, escola e comunidade, isso é, troca de saberes - o tradicional (a família), e o acadêmico (a escola), aproveitando o aluno como mediador e sujeito do processo, contribuindo, também, para seu amadurecimento como cidadão.

\section{REFERÊNCIAS}

ALBUQUERQUE, U. P.; ANDRADE, L. H. C. Conhecimento botânico tradicional e conservação em uma área de caatinga no estado de Pernambuco, Nordeste do Brasil. Acta Botanica Brasilica, São Paulo, v. 16, n. 3, p. 273-285, 2002.

AMOROSO, M. C. M. Uso e diversidade de plantas medicinais em Santo Antônio do Laverges, MT. Brasil. Acta Botânica, Brasília, p. 4-13, 2002.

AGÊNCIA NACIONAL DE VIGILÂNCIA SANITÁRIA (ANVISA). Plantas medicinais. Dispoível em: $<W w w$.anvisa.gov.br>. Acesso em: 23.sete.011.

BARATA, G. Farmácias vivas, medicina popular obtém reconhecimento científico. Ciência e Cultura, São Paulo, v. 55, n. 1, jan./mar. 2003.

CANDIDO, R. G. Nossos saberes não se restringem à escola: o que tem o Minuto Ecológico ver com isso? In: SANTOS, L. H. S dos. (Org.). Biologia dentro e fora da escola: meio ambiente, estudos culturais e outras questões. Porto Alegre: Mediação, 2003. 159 p. (cadernos de Educação Básica, 6).

CASCINO, F. Educação ambiental: princípio, história, formação de professores. São Paulo: SENAC, 1998.

CASTRO, H. G.; FERREIRA, F. A. A dialética do conhecimento no uso das plantas medicinais. Revista Brasileira de Plantas Medicinais, v. 3, n. 2, p. 19-21, 2001.

CORREA, Junior; MING, L. C.; SCHEFFER, M. C. Cultivo de plantas medicinais. Curitiba: Emater, 1994.

DIAS, J. E. A importância do uso de plantas medicinais em comunidades de periferia e sua produção através da agricultura urbana. Acta Hort., v. 569, p. 79, 2002. 
FAVILA, M. A. C. As plantas medicinais como instrumento de educação ambiental. Monografia (Especialização). Universidade Federal de Santa Maria, Santa Maria, 2004.

GARLET, T. M. B.; IRGANG, B. E. Plantas medicinais utilizadas na medicina popular por mulheres trabalhadoras rurais de Cruz Alta, Rio Grande do Sul, Brasil. Rev. Bras. PI. Med., Botucatu, v. 4, n.1, p. 9-18, 2001.

GUARIM-NETO, G.; SANTANA, S. R.; SILVA, J. V. B. Notas etnobotânicas de espécies de Sapindaceae Jussieu. Acta Botanica Brasilica, São Paulo, v. 14, n. 3, p. 167, 2000.

HERSHEY, D.R. Plant blindness: "we have met the enemy and he is us". Plant Science Bulletin, v. 48, p.7884, 2002.

LORENZI, H. Plantas medicinais no Brasil. Nova Odessa, SP: Instituto Plantarum, 2002.

LORENZI, H.; MATOS, F. J. de A. Plantas medicinais no Brasil: nativas e exóticas. 2. ed. Nova Odessa: Instituto Plantarum, 2008.

LUCIRIO, I; ARRUDA, G. Plantas na farmácia. Viva Saúde, p. 37-39, s.d.

MARODIN, S. M.; BAPTISTA, L. R. de M. O uso de plantas medicinais no município de Dom Pedro de Alcântara, Rio Grande do Sul, Brasil. Rev. Bras. PI. Med., Botucatu, v.4, n.1, p. 57-68, 2001.

MENDONÇA. A. R.V. Fitoterapia e enfermagem: aproximando o sistema e popular no serviço de saúde a domicilio. 1998. 87f. Dissertação (Mestrado) Universidade Federal de Santa Catarina Polo 1 Universidade Federal do Paraná Convenio Repesul, Curituba, 1998.

MATOS, E. L.. Breve histórico da legislação ambiental brasileira e dos movimentos ambientalistas. Curituba, Aracaju, v. 2, n. 1, p. 69-83, 1999.

MORIN, E. Os sete saberes necessários a educação do futuro. 4. edição, São Paulo/ Brasília: Cortez/ UNESCO (2000).

UOL NOTÍCIAS? CIÊNCIAS E SAÚDE. anvisa regulamenta uso de plantas medicinais de uso popular. Disponível em: <http://noticias.uol.com.br/ultnot/cienciaesaude/ultimas-noticias/2010/03/11/anvisaregulamenta-uso-de-plantas-medicinais-de-tradicao-popular.jhtm>. Acesso em: 09.set.2011.

RONDÔNIA, Secretaria de Estado de Indústria, Comércio, Ciência e Tecnologia. Divisão de Pesquisa. Flora regional na medicina caseira. Porto Velho, 1986. $38 \mathrm{p}$.

SANTOS et al. Construção de um jardim de plantas medicinais e aromáticas: a educação ambiental valorizando o saber popular. Revista et al, 03.mar.2010.

SIMÕES, M.O.; SCHENKEL, E.P; GOSMANN, G.; DE MELLO, J.C.P.; MENTZ, L.A.; PETROVICK, P.R. Farmacognosia: da planta ao medicamento. 2. ed. Porto Alegre/Florianópolis: Editora da Universidade UFSC, 2000. 
SOSSAE, F.C. Plantas medicinais. Disponível em: <http://educar.sc.usp.br/biologia/prociencias/medicinais>. Acesso em: 17.set.2011.

SOUZA, G.S. Tratado descritivo no Brasil em 1587. São Paulo: Companhia Editora Nacional e Editora da USP, 1971.

SOUZA, M.V.O. de et al. Atividades de ensino de Botânica no projeto embarcando no bondinho da ciência PPA/UNIRIO. In: CONGRESSO NACIONAL DE BOTÂNICA, 58., 2007, São Paulo. Anais... São Paulo: Sociedade Botânica do Brasil, 2007. 1 CD-ROM.

VENDRUSCULO, G. S.; SOARES, E. L. C.; EISINGER, S. M.; ZACHIA, R. A. Estudo etnobotânico do uso dos recursos vegetais em São João do Polêsine - RS, no período de outubro de 1999 a junho de 2001 - IIEtnotaxonomia: critérios taxonômicos e classificação folk. Rev. Bras. PI. Med., Botucatu, v.7, n.2, p.37-43, 2005.

VENDRUSCULO, G. S.; RATES, S. M. K.; MENTZ, L. A. Plantas utilizadas como medicinais pelos moradores do bairro Ponta Grossa, Porto Alegre, Rio Grande do Sul, Brasil. In: VENDRUSCULO, G. S.; RATES, S. M. K.; MENTZ, L. A. Guia informativo. Porto Alegre, 2008. 46 p.

WEBARTIGOS. Disponível em: <http://www.webartigos.com/articles/32089/1/EDUCACAO-AMBIENTALversos-Plantas-Medicinais/pagina1.html\#ixzz1XVeE7HKH>. Acesso em: 09.set.2011. 